\title{
AVALIAÇÃO DAS CAUSAS DE RETENÇÃO EM QUÍMICA GERAL NA UNIVERSIDADE FEDERAL DO AMAZONAS
}

\author{
Klenicy K. L. Yamaguchi ${ }^{a}$ ** Jath da Silva e Silva ${ }^{a}$ \\ anstituto de Saúde e Biotecnologia, Universidade Federal do Amazonas, 69460-000 Coari - AM, Brasil
}

Recebido em 20/08/2018; aceito em 10/12/2018; publicado na web em 14/02/2019

\begin{abstract}
EVALUATING OF LOW PASS RATES IN GENERAL CHEMISTRY AT THE FEDERAL UNIVERSITY OF AMAZON. Failing classes is one of the main causes students are held back in universities, which in turn has several academic, social and economic impacts. This study aims to identify factors associated with students flunking General Chemistry, as well as to propose institutional interventions that can remedy these setbacks. The methodology used was based on a conceptual model of nontraditional undergraduate students, evaluating student academic outlook and relating that with institutional data on subject pass rate. Results showed it was possible to correlate variables that influence pass rates in General Chemistry, highlighting the following: busy schedule, study method, high class load per semester, deficiencies in basic chemistry and math, and socioeconomic factors. Results in this work help identify challenges that can aid in developing strategies to eradicate or minimize failing in General Chemistry in higher education institutions in Brazil.
\end{abstract}

Keywords: super senior; teaching Chemistry; Amazon.

\section{INTRODUÇÃO}

O número de ingressantes nas instituições de educação superior cresceu nos últimos anos. Segundo os dados do Censo da Educação Superior feito pelo Instituto Nacional de Estudos e Pesquisas Educacionais Anísio Teixeira - INEP, em 2016 o aumento foi de $1,9 \% .^{1}$ Paralelamente, cresceram também os índices estatísticos sobre a evasão universitária, principalmente os relacionados aos cursos de licenciatura que chegam a valores superiores a $50 \%$, como os descritos para as licenciaturas de Física $(57,2 \%)$, Química $(52,3 \%)$ e Matemática (52,6\%), o que agrava consideravelmente o problema do grande déficit de professores de ciências.

Trabalhos realizados sobre evasão apontam a permanência prolongada em disciplinas consideradas difíceis como um dos fatores que contribuem para a desistência do curso. ${ }^{2-6}$ Entre elas, tem-se a Química Geral, comumente dividida em teórica e experimental. As dificuldades provenientes dessa disciplina acabam sendo determinantes para os recém universitários pois é, frequentemente, o primeiro contato dos discentes com o universo da Química na universidade, abrindo portas para as disciplinas que a seguem, como química orgânica e bioquímica para os cursos da área de saúde e as demais químicas: analítica, inorgânica e físico-química, para os cursos de exatas, engenharias e licenciaturas.

A retenção em Química Geral vem permeando discussões sobre o ensino de graduação, tanto nacional quanto internacionalmente, indicando a necessidade do aprofundamento nos estudos a respeito, buscando suas causas e estratégias para redução. As pesquisas na área contribuem para o avanço do conhecimento sobre o processo de permanência prolongada nessa disciplina e entre os fatores relacionados, citam-se: docentes que ministram essa disciplina em formato tradicional; dificuldades no processo de aprendizagem dos discentes; baixo nível de conhecimento básico dos alunos e a pouca aplicação dessa disciplina nos conceitos no cotidiano. ${ }^{4-7}$ Para Cracolice e Busby, ${ }^{5}$ essa disciplina na faculdade vai muito além da aquisição de conhecimento de conteúdo e precisa preparar o discente para o desenvolvimento da capacidade de raciocínio e para o meio científico.

*e-mail: klenicy@gmail.com
Segundo Pastoriza et al., ${ }^{3}$ as dificuldades encontradas pelos alunos levam a um alto índice de reprovação e, quando a forma produtiva de assimilar os saberes não é encontrada ao repetir a disciplina, contribui consideravelmente para a evasão do curso.

A retenção pode ser definida como a condição em que o estudante demanda um tempo maior do que o previsto na matriz curricular, tendo que cursar novamente uma disciplina em que não tenha sido aprovado. Segundo Andrade, Meira e Vasconcelos ${ }^{8}$ esse índice elevado de reprovação pode ocorrer pela pouca afinidade com o curso selecionado, fragmentação da estrutura curricular, dificuldades de adaptação à organização universitária e fatores endógenos inerentes à relação ensino e aprendizagem, e exógenos, como motivações financeiras.

Verifica-se que os efeitos desse fenômeno são danosos e bem perceptíveis, não somente no cunho acadêmico, mas também econômico e social. A ampliação da duração do curso retarda a inserção de profissionais de nível superior no mercado profissional e representa um acréscimo de recursos para a instituição (pessoal, administrativo, estrutural e financeiro), gerando um aumento de investimentos (energia e tempo). ${ }^{2,9}$

Dificuldades na determinação de políticas adequadas que possam reduzir a incidência desse fenômeno são perceptíveis e esse trabalho buscou identificar os fatores associados à retenção e às ações de intervenção institucionais que possibilitam a melhoria desses altos índices. Para tanto, foi realizado um levantamento das principais dificuldades encontradas na perspectiva dos acadêmicos em Química Geral no curso de Ciências do Instituto de Saúde e Biotecnologia da Universidade Federal do Amazonas e realizada a análise dos dados de retenção nos últimos 10 anos.

O campus possui sede no município de Coari, localizado na região do Médio Solimões, cerca de $363 \mathrm{Km}$ em linha reta da capital do estado, Manaus. Situa-se em uma área importante pela exploração do gás e do petróleo. Atende aos municípios de Alvarães, Anamã, Anori, Beruri, Codajás, Maraã, Tefé e Uarini, que assim como a sede, apresenta os rios como principal meio de transporte, o que dificulta o acesso da população as universidades da capital. O curso de Ciências: Biologia e Química foi criado considerando as diretrizes nacionais para os cursos superiores do MEC por meio da implantação da modalidade "licenciatura com habilitação dupla" visando atender a 
carência de professores nos campos das Ciências de um modo geral, bem como Biologia e Química, especificamente.

\section{METODOLOGIA}

Este trabalho parte de uma metodologia integrante entre uma pesquisa bibliográfica e uma pesquisa de campo. A pesquisa adotou abordagem qualitativa e quantitativa com caraterísticas de estudo descritivo e caráter exploratório buscando correlações e explicações para a problemática da alta retenção na disciplina de Química Geral.

A primeira etapa consistiu na revisão bibliográfica e busca de teorias para fundamentação do estudo incluindo o levantamento de dados a partir do sistema acadêmico com intuito de embasar o estudo de campo. Buscou-se descobrir a existência de relações entre a retenção em Química Geral e as variáveis baseadas no Modelo Conceitual de Desgaste de Estudante não tradicionais de Bean e Metzner ${ }^{10}$ associadas aos seguintes critérios: 1) desempenho acadêmico; 2) variáveis acadêmicas; 3) experiência e objetivos educacionais e 4) variáveis ambientais. Novos itens foram incluídos tendo em vista o interesse de enriquecer as associações, como a afinidade com a disciplina e a perspectiva de intervenção relacionada ao discente, ao docente e à instituição.

Os dados utilizados na pesquisa de campo foram obtidos por meio de questionários aplicados aos acadêmicos, caracterizando o trabalho como um estudo de caso. A amostragem participante foi composta por estudantes do Instituto de Saúde e Biotecnologia da Universidade Federal do Amazonas (ISB-UFAM), no município de Coari, Amazonas, Brasil. O critério adotado para seleção dos alunos foi a retenção na disciplina de Química Geral teórica. Para tanto, foram convidados a participar os discentes de uma turma extra do curso de Ciências: Biologia e Química formada por 38 indivíduos que após assinarem o termo de consentimento livre e esclarecido receberam o questionário contendo 27 perguntas abertas e fechadas.

A terceira etapa do percurso metodológico constituiu-se da coleta de dados da instituição (dados secundários) relativos à situação acadêmica dos alunos relacionados ao percentual de aprovação e retenção, além da natureza deste último. A retenção foi calculada baseando-se na resolução vigente, considerando em retenção os estudantes que reprovaram por falta, trancamento ou nota inferior à média 5,0 e considerou o período de 2007 à 2017.

Os dados obtidos foram tabulados e analisados quantitativamente de modo a apresentá-los sob a forma de percentual e de número absoluto. A análise de dados deu-se por meio da proporção entre o número de indivíduos que forneceram cada resposta e o total de pessoas que responderam à pergunta. Além disso, também se pôde aplicar, sobre o material coletado, uma análise qualitativa das dificuldades. Os dados obtidos foram submetidos à análise estatística calculando a média, moda e mediana utilizando o programa de estatística R $2.14 .0^{\circledR}$ para Windows.

\section{RESULTADOS}

O foco desse estudo foi a identificação de fatores associados ao fenômeno da permanência prolongada dos discentes na disciplina de Química Geral no curso de Ciências: Biologia e Química oferecidos nos 10 anos de existência do Instituto de Saúde e Biotecnologia fazendo correlações entre as variáveis e aprofundando a compreensão do problema com proposta de soluções. Os resultados podem ser compreendidos como formados pelas seguintes etapas: a) caracterização de perfis dos discentes retidos; b) elaboração das causas da retenção; c) identificação e apresentação de estratégias de ações voltadas à redução do tempo prolongado na disciplina.

\section{Caracterização dos sujeitos}

Os discentes que participaram da pesquisa eram $61 \%$ do gênero feminino e $39 \%$ do masculino. A amostragem era de acadêmicos de períodos diferentes, sendo o maior percentual localizado entre os discentes do quarto período, seguido de $16 \%$ do segundo, $13 \%$ do sexto e os demais percentuais divididos entre o oitavo (8\%) e décimo $(8 \%)$ (Figura 1A). Em relação à idade, $3 \%$ corresponderam à faixa etária de até 18 anos, seguidos de 53\% com idade entre 19 a 21 anos, $32 \%$ de 22 a 24 anos e $12 \%$ com idade acima de 25 anos. Segundo o censo 2016, a idade média com a qual os estudantes ingressam na faculdade é de aproximadamente 21 anos, o que corrobora com os dados encontrados nessa pesquisa. ${ }^{11}$

\section{Dados sobre a retenção}

Ao ser analisado a quantidade de reprovações em Química Geral, verificou-se uma correlação com a periodização, em que quanto maior o período, mais reprovações eram verificadas na amostra entrevistada. Um maior percentual foi detectado em alunos que estavam repetindo a disciplina pela terceira vez (Figura 1B).

Entre as disciplinas Química Geral teórica e Química Geral experimental, verificou-se uma discrepância entre os valores de aprovação. Enquanto no universo analisado apenas 3 pessoas afirmaram que ficaram retidos na disciplina experimental, $89 \%$ dos discentes já ficaram retidos pelo mais de uma vez na disciplina teórica e $26 \%$ reprovaram mais de 2 vezes. Esses dados podem ser subsidiados pelos dados obtidos sobre índices de reprovação/aprovação nessas disciplinas nos anos anteriores, conforme a Figura 2.

O modelo gráfico de caixa ou boxplot é uma ferramenta estatística utilizada para avaliar a distribuição empírica dos dados identificando nesse trabalho a relação entre a média das retenções priorizando a faixa comum e excluindo as variáveis independentes. Por meio dessa ferramenta pôde-se revelar os percentuais médios significativos no processo (Figura 2A e 2B). Verificou-se que nos 10 anos de existência do campus, a média de retenção Química Geral experimental foi de 26,46\% e mediana de 22,64\%. Em Química Geral teórica a média foi de $56,25 \%$ e mediana de $70,18 \%$.

Na Figura 2B é possível visualizar o quanto o índice de retenção foi superior ao de aprovação nas turmas em que essa disciplina foi ofertada. Em apenas 31\% das ofertas o índice de aprovação foi superior ao de retenção e, analisando as quatro últimas ofertas, observa-se um aumento gradativo desse índice.

Segundo a Lei de Diretrizes e Bases (LDB 9394), os tipos de retenção podem ser divididos em 3 grupos: reprovação por nota, reprovação por falta e trancamento. Os dados institucionais a respeito do índice de aprovação e retenção em Química Geral no período de 2007 a 2017 podem ser visualizados na Figura 3. Ao se observarem as informações contidas na tabela, evidencia-se que o problema está associado ao baixo rendimento dos alunos nas atividades avaliativas da disciplina em comparação com a frequência dos alunos, visto que o índice de retenção por nota é predominante ao de reprovação por frequência.

O risco de retenção de alunos com uma reprovação é 2,3 vezes o daqueles que não reprovaram. Para indivíduos com duas a cinco reprovações o risco é de 4,8 vezes, enquanto que para aqueles com mais de seis o risco é de 41,7 vezes. $^{2}$

No que se refere à média de retenção no ISB-UFAM, os índices que norteiam são altos, e acabam alertando para um problema que pode culminar em um problema institucional. Essa disciplina é pré-requisito para as outras químicas (orgânica, inorgânica, analítica e físico-química). Com esse número alarmante de reprovações, a evasão poderá ser uma realidade próxima por meio do jubilamento 
A Distribuição de número de alunos por
período

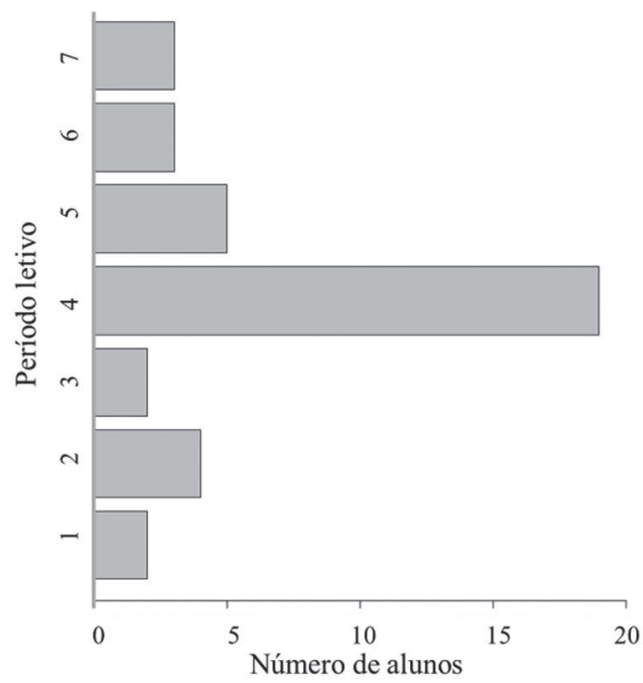

B Distribuição de número de alunos por número de vezes que cursou a disciplina

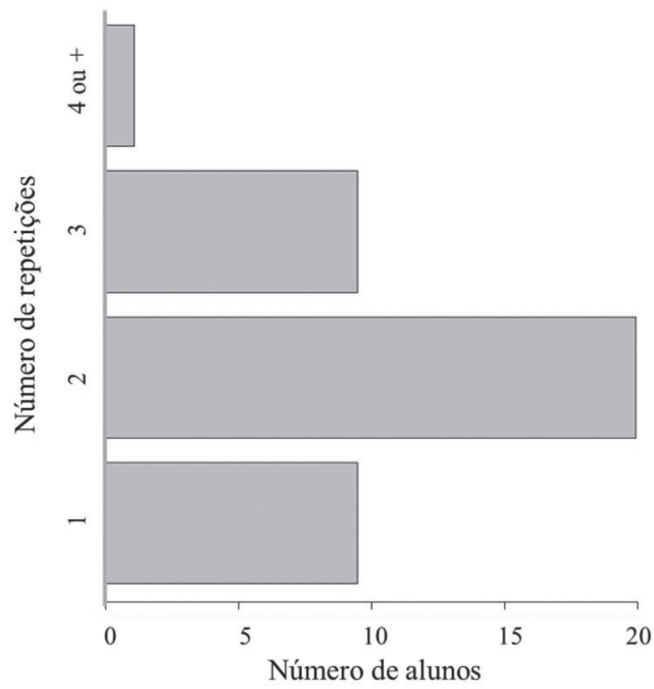

Figura 1. Dados sobre as retenções em Química geral. A) caracterização dos períodos dos acadêmicos; B) Quantidade de retenções por aluno

Média de retenção em Química Geral - 2007 à 2017
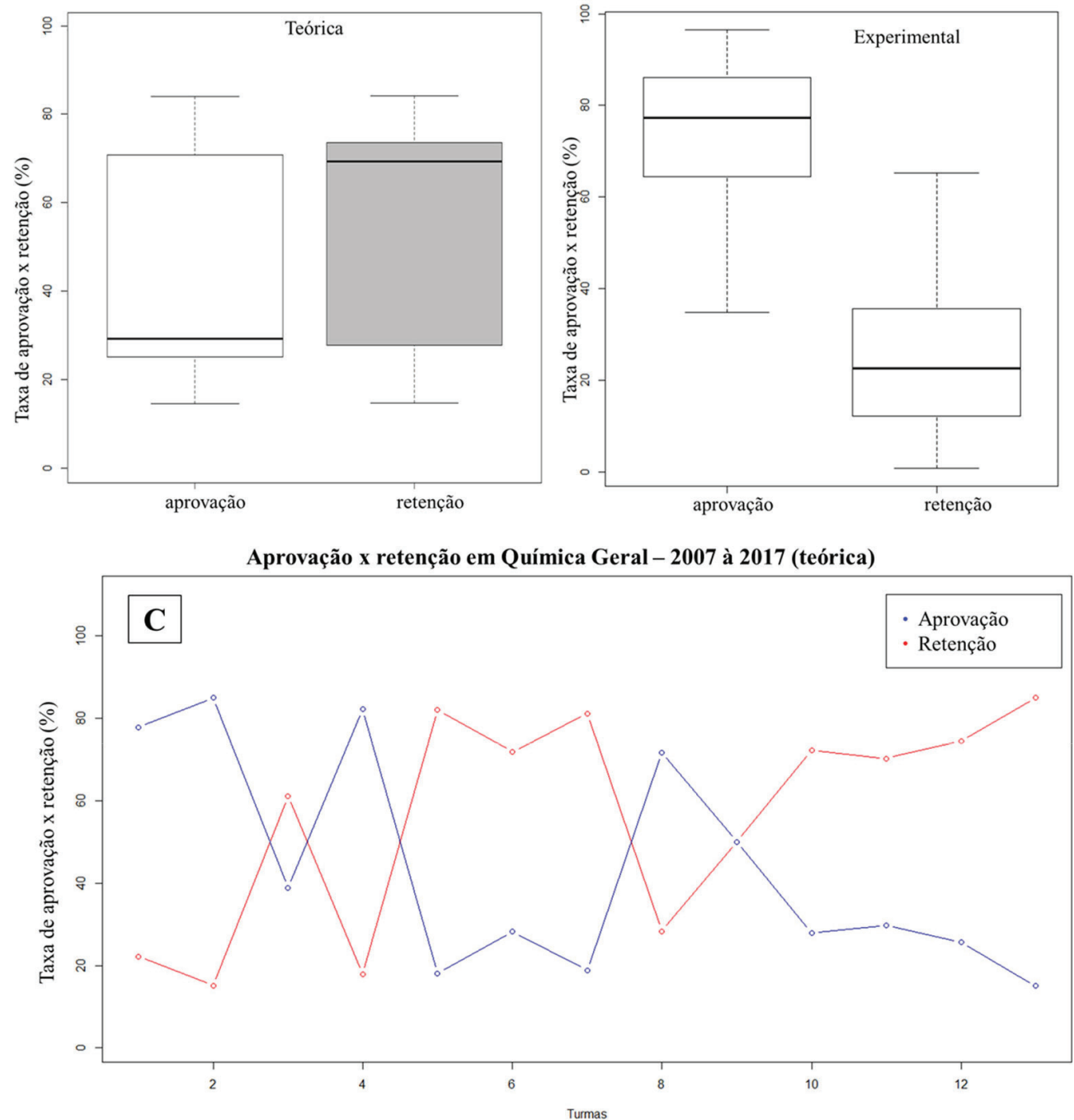

Figura 2. Percentual de aprovação e retenção em Química Geral. A) Percentual médio da disciplina Química Geral Teórica; B) Experimental e C) índice de aprovação e retenção no período de 2007 à 2017 de Química Geral teórica 


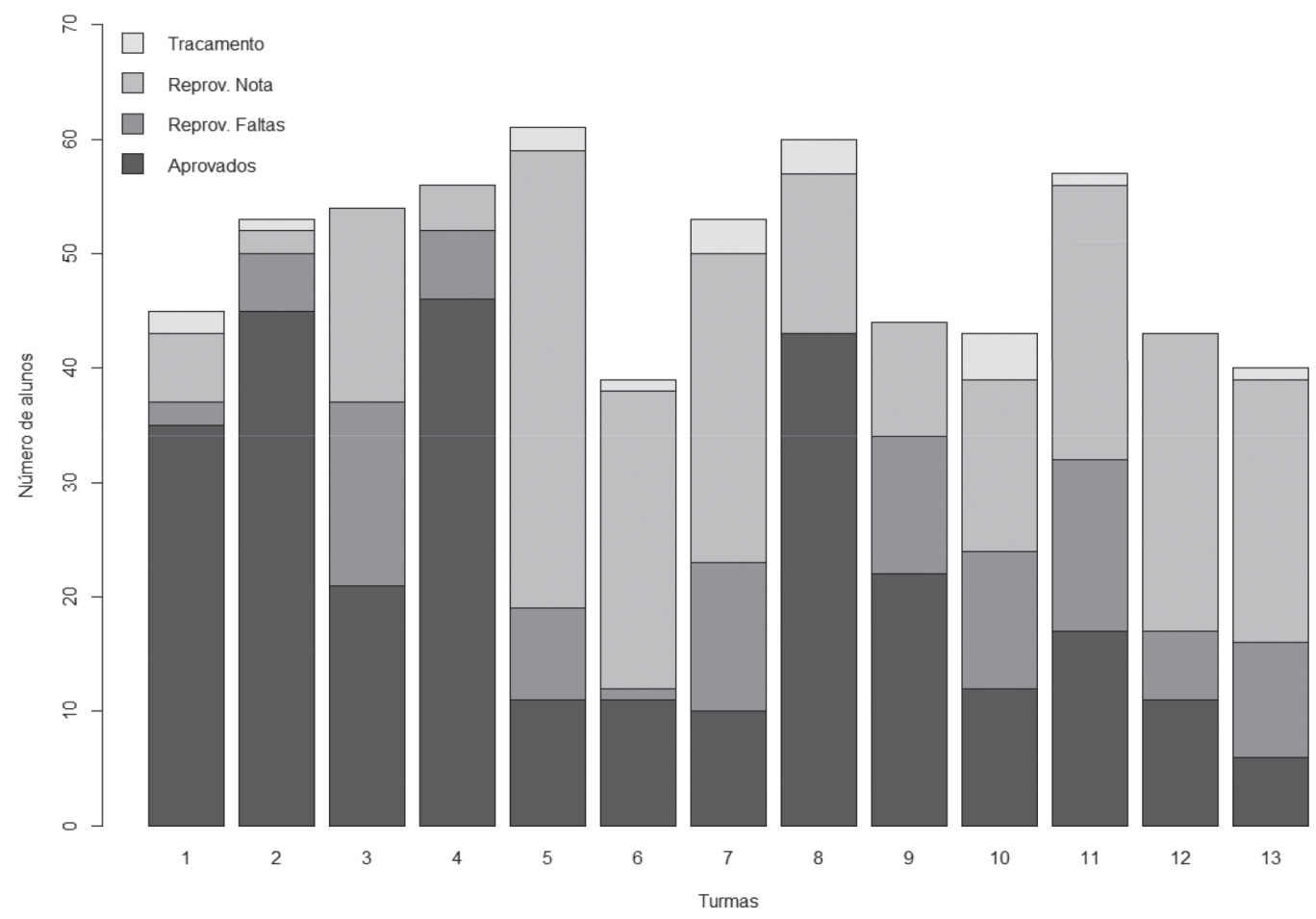

Figura 3. Aproveitamento da disciplina de Química Geral

dos discentes que não conseguirem em tempo hábil finalizar o curso. Atualmente o curso de Ciências: Biologia e Química é de 10 períodos semestrais, ou seja, cinco anos. Se houver mais que quatro retenções, há uma alta probabilidade de completar o tempo de jubilamento, levando em consideração que a disciplina é comumente ofertada uma vez ao ano.

Os dados institucionais refletem os resultados obtidos pelo questionário na turma de Química Geral, a partir do qual se verificou que $79 \%$ dos discentes reprovaram por nota, seguido de $18 \%$ de reprovação por falta e $3 \%$ por trancamento que envolviam motivos diversos que não foram objeto deste trabalho. Esses dados foram sustentados quando na questão posterior $85 \%$ dos discentes afirmaram que frequentaram a disciplina até o final do período e apenas $15 \%$ afirmaram que não tiveram frequência até o final do período. Um ponto que merece ser analisado vem do fato de os discentes, ao terem reprovação por falta e por nota, segundo o sistema, serem computados como reprovação por falta. Dessa forma, o índice de reprovações por nota pode conter um percentual maior do que é verificado pelos índices encontrados. Esses podem ser visualizados por meio da Tabela 1.

Ao serem questionados sobre as consequências da retenção na disciplina de Química Geral, os discentes foram quase unânimes nas respostas dissertativas, ao citarem o atraso no curso devido as disciplinas consideradas pré-requisito, levando-se em consideração que no ISB-UFAM a disciplina de Química Geral é ofertada apenas uma vez ao ano e uma reprovação na disciplina tem como consequência a permanência do discente durante um ano a mais. Para minimizar essa situação, vem sendo realizadas turmas extras nos períodos em que essa disciplina é oferecida, o que explica o fato de haver mais de uma turma durante o mesmo período na Tabela 1 , tendo em vista que, por ser dos períodos iniciais, os calouros acabam preenchendo a maior parte das vagas ofertadas, com cerca de 5 vagas remanescentes para os discentes que não estão periodizados.

Ciribelli e Ferreira ${ }^{12}$ afirmam que a retenção nas disciplinas iniciais tem dificultado a evolução dos acadêmicos dentro do curso, sendo possível, assim, levantar a hipótese de que o fato de o estudante não apresentar esse desenvolvimento contribua para os casos de evasão, tendo em vista que ambos ocorrem no ambiente universitário e envolvem os mesmos tipos de autores (estudantes, professores, familiares e outros pontos em comum). Segundo dados do censo de 2016, a evasão nos cursos de Química chega a 80\% em algumas regiões do Brasil e Química Geral Teórica está inserida entre as três disciplinas em que houve maior percentual de reprovação entre os discentes jubilados, acompanhados de Introdução a ciência da computação e álgebra linear, sendo a reprovação por nota com cerca de $10 \%$ e reprovação por nota com $18 \%$. $^{9}$

Verificou-se que $50 \%$ dos discentes já pensaram em algum momento em desistir ou trancar o curso por conta da retenção e 58\% dos entrevistados afirmaram que conhecem alguém que desistiu ou fez reopção por outro curso devido à retenção na disciplina ou pelas consequências dessa retenção. Ao avaliarem o histórico, apenas cerca de um quarto do percentual $(25 \%)$ dos discentes afirmaram que não reprovaram em outras disciplinas, dos quais 36\% foram em uma única disciplina, $32 \%$ em duas, $21 \%$ em três e $11 \%$ em 4 ou mais. Leva-se em consideração que não foi avaliado quantas vezes uma mesma disciplina foi realizada, e sim as diversidades das disciplinas.

\section{Dificuldades}

Após avaliar o desempenho acadêmico, seguiu-se as análises do Modelo Conceitual de Desgaste de Estudante não tradicionais avaliando variáveis acadêmicas, de experiência e objetivos educacionais e variáveis ambientais com a análise socioeconômica dos participantes. Assim como no modelo original da metodologia de Bean e Metzner, ${ }^{10}$ pode-se fazer possíveis relações entre a quantidade de retenção, as variáveis explicativas e a perspectiva dos acadêmicos. Os principais resultados podem ser visualizados na Tabela 2.

\section{Afinidade com a disciplina}

Na turma analisada verificou-se que como o curso é de ciências, há disciplinas da área de biologia e de química. Alguns discentes 
Tabela 1. Dados sobre a retenção em Química Geral

\begin{tabular}{|c|c|c|c|}
\hline Questões & Alternativas & $\mathrm{N}$ & Percentual \\
\hline \multirow{4}{*}{$\begin{array}{l}\text { 1) Qual foi o seu tipo de } \\
\text { retenção em Química } \\
\text { Geral teórica? }\end{array}$} & Reprovação por nota & 31 & $79 \%$ \\
\hline & Reprovação por falta & 2 & $5 \%$ \\
\hline & Trancamento & 1 & $3 \%$ \\
\hline & Não preencheu & 5 & $13 \%$ \\
\hline \multirow{5}{*}{$\begin{array}{l}\text { 2) Quais as consequên- } \\
\text { cias de ficar reprovado } \\
\text { em Química Geral? } \\
\text { (dissertativa) }\end{array}$} & $\begin{array}{l}\text { Ter que cursar a disciplina } \\
\text { com outras turmas }\end{array}$ & 1 & $3 \%$ \\
\hline & $\begin{array}{c}\text { Retenção acadêmica: } \\
\text { Atraso em disciplinas pré- } \\
\text { requisitos: }\end{array}$ & 26 & $67 \%$ \\
\hline & $\begin{array}{l}\text { Não compreensão dos } \\
\text { assuntos posteriores nas } \\
\text { outras matérias }\end{array}$ & 5 & $13 \%$ \\
\hline & Diminuição do coeficiente & 1 & $3 \%$ \\
\hline & Não respondeu & 7 & $18 \%$ \\
\hline \multirow{2}{*}{$\begin{array}{l}\text { 3) Você chegou a fre- } \\
\text { quentar a disciplina até } \\
\text { o final do período? }\end{array}$} & Sim & 33 & $85 \%$ \\
\hline & Não & 5 & $15 \%$ \\
\hline \multirow{3}{*}{$\begin{array}{l}\text { 4) Você pensou em } \\
\text { algum momento em de- } \\
\text { sistir ou trancar o curso } \\
\text { por conta da retenção } \\
\text { em Química Geral } \\
\text { Teórica? }\end{array}$} & Sim & 16 & $44 \%$ \\
\hline & Não & 18 & $50 \%$ \\
\hline & Parcialmente & 2 & $6 \%$ \\
\hline \multirow{2}{*}{$\begin{array}{l}\text { 5) Você conhece alguém } \\
\text { que tenha desistido do } \\
\text { curso ou feito a reopção } \\
\text { por outro curso devido a } \\
\text { retenção na disciplina? }\end{array}$} & Sim & 22 & $58 \%$ \\
\hline & Não & 16 & $42 \%$ \\
\hline \multirow{2}{*}{$\begin{array}{l}\text { 6) Você já reprovou em } \\
\text { outras disciplinas? }\end{array}$} & $\operatorname{Sim}$ & 29 & $76 \%$ \\
\hline & Não & 9 & $24 \%$ \\
\hline \multirow{4}{*}{ 7) Se sim, Quantas? } & 1 & 10 & $36 \%$ \\
\hline & 2 & 9 & $32 \%$ \\
\hline & 3 & 6 & $21 \%$ \\
\hline & 4 ou mais & 3 & $11 \%$ \\
\hline
\end{tabular}

afirmaram que já haviam completado as disciplinas da área de biologia e alguns até defendido o trabalho final de curso, no entanto, não haviam prosseguido no viés químico devido à retenção em Química Geral.

$\mathrm{Na}$ avaliação, $79 \%$ dos discentes afirmaram que se pudessem separar a habilitação do curso, optariam por selecionar apenas uma área de concentração. Esse percentual é complementado pela questão seguinte, em que ao serem questionados sobre quais das duas áreas eles se identificaram mais, a maior parte dos estudantes analisados (63\%) afirmaram que se identificam mais com Biologia, seguido de $19 \%$ que se identificavam com Química e 18\% com ambas. Além do que, afirmam que a retenção em Química Geral teórica diminui a preferência pela área de concentração em química, seja total ou parcialmente.

A fim de apresentar, em linhas gerais, os critérios e motivos para a escolha do curso, considerou-se a Figura 4 como forma de nortear a análise dessa pesquisa.

Os dados encontrados são condizentes com as questões anteriores no que diz respeito a preferência das disciplinas do eixo em biologia. Outro ponto relevante dar-se-á pelo fato do maior percentual dos discentes terem selecionado esse curso pela nota acessível no processo
Tabela 2. Principais causas da retenção em Química Geral

\begin{tabular}{lccc}
\hline Questão & Alternativas & $\mathrm{N}$ & Percentual \\
\hline \multirow{3}{*}{$\begin{array}{l}\text { 1) Você se identifica mais com } \\
\text { Química ou Biologia? }\end{array}$} & Biologia & 24 & $63 \%$ \\
\cline { 2 - 4 } & Química & 7 & $18,5 \%$ \\
\cline { 2 - 4 } & Ambas & 7 & $18 \%$ \\
\hline $\begin{array}{l}\text { 2) Se você pudesse separar o curso, } \\
\text { você optaria por selecionar apenas } \\
\text { uma área de concentração? }\end{array}$ & Sim & 30 & $79 \%$ \\
\cline { 2 - 4 } & Não & 8 & $21 \%$ \\
\hline
\end{tabular}

3) Você acredita que a retenção em Química Geral diminua a sua preferência pela área de concentração em Química?

\begin{tabular}{lll} 
Sim & 17 & $45 \%$ \\
\hline Não & 11 & $29 \%$ \\
\hline
\end{tabular}

4) Você possui algum vínculo empregatício ou trabalho autônomo?

5) Você mora com:

Parcialmente $10 \quad 26 \%$

\begin{tabular}{ccc} 
Sim & 6 & $16 \%$ \\
\hline Não & 32 & $84 \%$ \\
\hline
\end{tabular}

Pais $26 \quad 68 \%$

\begin{tabular}{ccc} 
Pais & 26 & $68 \%$ \\
\hline Sozinho & 3 & $8 \%$ \\
\hline Cônjuge & 4 & $11 \%$ \\
\hline Amigos & - & - \\
\hline Outros & 5 & $13 \%$ \\
\hline
\end{tabular}

6) Você recebe alguma bolsa ou auxílio promovido pela UFAM?

7) Se sim, qual?

\begin{tabular}{ccc} 
Sim & 14 & $35 \%$ \\
\hline Não & 24 & $65 \%$ \\
\hline
\end{tabular}

\begin{tabular}{ccc} 
Bolsa trabalho & 1 & $7 \%$ \\
\hline Auxílio moradia & 2 & $14 \%$ \\
\hline Auxílio acadêmico & 11 & $79 \%$
\end{tabular}

8) Quantas horas semanais você dedica para estudar?

\begin{tabular}{ccc}
$1-2$ & 11 & $30 \%$ \\
\hline $3-4$ & 17 & $46 \%$ \\
\hline $5-6$ & 7 & $19 \%$ \\
\hline mais que 7 & 2 & $5 \%$
\end{tabular}

\begin{tabular}{llll} 
Anotações da aula & 30 & $22 \%$ \\
\hline
\end{tabular}

livro indicado pelo $28 \quad 21 \%$

9) Em que material didático você costuma estudar? (selecione todas as opções que você utiliza)

10) Qual o conteúdo que você mais sente dificuldade?

\begin{tabular}{ccc} 
docente & 28 & $21 \%$ \\
\hline $\begin{array}{c}\text { livro comple- } \\
\text { mentar }\end{array}$ & 13 & $10 \%$ \\
\hline artigos & 12 & $9 \%$ \\
\hline sites da internet & 26 & $19 \%$ \\
\hline vídeo aulas & 26 & $19 \%$ \\
\hline Estequiometria & 14 & $29 \%$ \\
\hline $\begin{array}{c}\text { Cálculos } \\
\text { matemáticos }\end{array}$ & 5 & $11 \%$ \\
\hline Balanceamento & 14 & $29 \%$ \\
\hline Reações químicas & 6 & $13 \%$ \\
\hline $\begin{array}{c}\text { Ligações químicas } \\
\text { Funções inorgâni- } \\
\text { cas }\end{array}$ & 4 & $8 \%$ \\
\hline Estrutura atômica & 1 & $2 \%$ \\
\hline
\end{tabular}

de seleção. Os estudantes revelam que encontram nas licenciaturas uma forma de ingresso com baixa concorrência no ensino superior.

Atualmente a entrada dos discentes nas universidades federais é principalmente através do Exame Nacional do Ensino Médio (ENEM). Nesse processo, os estudantes fazem uma prova de conhecimentos gerais e somente após a computação das notas é realizada a seleção do curso. Esse é um assunto abordado por muitos trabalhos 


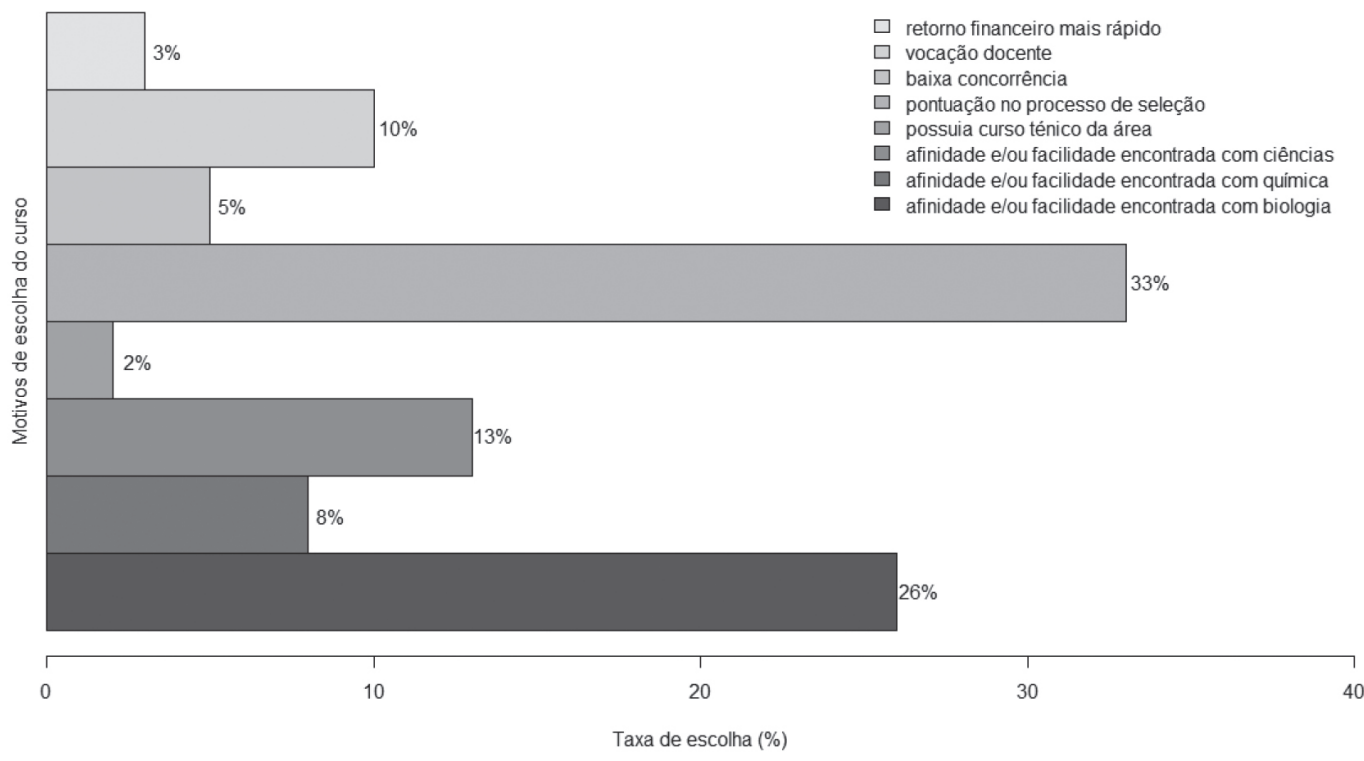

Figura 4. Critérios para seleção do curso universitário

científicos em que em alguns casos os discentes optam pelo curso em que possuem pontuação para entrar e não necessariamente nos que tem afinidade ou que sonharam cursar.

Verificou-se que apenas $10 \%$ dos discentes afirmaram que selecionaram o curso pela "vocação docente". As discussões que permeiam esse tema são retratadas de maneira diversa e nos mais variados contextos, sendo uma temática importante que visa auxiliar na compreensão da complexidade que envolve a escolha docente como profissão.

A vocação profissional é a tendência ou habilidade natural construída pelo indivíduo para exercer uma profissão. No entanto, as pesquisas no campo de educação têm demonstrado que a atuação não se restringe apenas na vocação e nem ao domínio de um conjunto de técnicas aprendidas no curso de formação, sendo um emaranhado complexo de variáveis. ${ }^{13-15}$ Dessa forma, o indivíduo que não consegue reconhecer-se pertencente a esse grupo, tende a distanciar-se, ocasionando frequentemente conflitos ao reconhecerem que o curso que optam não corresponde às expectativas profissionais almejadas..$^{2,4}$

\section{Metodologia de estudo}

Um outro ponto que merece ser analisado é relacionado à metodologia de estudo dos discentes. O ingresso a um curso universitário, seja por meio de um vestibular ou do ENEM, não garante que os mesmos apresentem maturidade para estudar. Autores descrevem que há um grande impacto na forma como os discentes encaravam a metodologia de estudo no Ensino Médio, em que conseguiam na véspera abranger todo o conteúdo da prova, para a situação na universidade, em que há uma maior quantidade de assuntos e que precisa ser estudado com antecedência.

A educação no Ensino Básico (Fundamental e Médio) difere-se consideravelmente da realidade de um ensino superior, variando desde a didática até a formatação dos trabalhos exigidos nos mesmos. Ao ingressarem num curso superior, frequentemente o aluno revela um despreparo para o planejamento dos estudos das disciplinas e se depara com diversos campos de atuação que o levará a amadurecer para a sua nova realidade. ${ }^{16}$ Como a disciplina Química Geral é ofertada comumente nos períodos iniciais, percebe-se uma falta de amadurecimento universitário oriundo dos discentes por não saberem a metodologia de como estudar. Nesse sentido, estudos internacionais confirmam os dados encontrados neste trabalho ao relatarem que muitos alunos se chocam ao ingressarem na universidade devido às abordagens pedagógicas serem distintas das do Ensino Médio, por vezes inadequadas ao perfil desse aluno, e à integração de novas informações e conhecimentos. ${ }^{6}$

A questão 8 (Tabela 1) constata dados preocupantes sobre os acadêmicos em relação a quantidade de horas semanais que eles se dedicam para estudar. Verificou-se que mais que $76 \%$ dos discentes afirmam que utilizam menos que 35 minutos diários para essa finalidade e somente $5 \%$ afirmam que estudam mais que 7 horas semanais, o que equivale a cerca de 1 hora diária. $19 \%$ estudam entre 5 e 6 horas e o maior percentual (46\%) dos estudantes afirmam que disponibilizam 3-4 horas para rever os conteúdos e realizar exercícios, seguidos de $30 \%$ que reconhecem que estudam somente de 1 ou 2 horas semanais

Segundo alguns autores, essa disciplina confronta os alunos com muito conteúdo e pouco tempo para assimilar o que é ministrado. ${ }^{17,18}$ E o tempo descrito pelos discentes nessa pesquisa torna-se insuficiente para que ocorra um maior aproveitamento da disciplina. Faz-se necessário um tempo maior para que ocorra o amadurecimento do estudante e então ele comece a encarar os problemas de frente. Para Pastoriza et al., ${ }^{3}$ muitos alunos só assistem aula e vão estudar na semana de prova e somente depois da avaliação descobrem que não estudaram o suficiente.

Os dados encontrados nesse trabalho são condizentes com o artigo de Jesus et al. ${ }^{4}$ no qual os autores descrevem que a maioria dos discentes dedicam apenas $2 \mathrm{~h}$ semanais aos seus estudos individuais fora da sala de aula. Nesse artigo os autores alertam para o fato de a distribuição dessas horas semanais ainda estarem divididas entre as disciplinas do período, em que com um número médio de cinco disciplinas, $2 \mathrm{~h}$ semanais passa a ser um tempo extremamente pequeno para a capacidade do aprendizado, explicando assim as notas baixas obtidas na disciplina.

No que se refere ao material didático que os alunos costumam estudar, os índices norteiam que $38 \%$ baseiam-se em vídeo aulas ou sites da internet, seguidos de $31 \%$ que estudam pelo livro indicado pelo docente como referência bibliográfica ou livros complementares, $22 \%$ utilizam as anotações das aulas e apenas $9 \%$ buscam artigos científicos. 


\section{Perfil socioeconômico}

Analisando o perfil socioeconômico dos discentes, examinou-se que $84 \%$ não trabalham. Ao serem questionados sobre a moradia, $68 \%$ moram com os pais, $11 \%$ com o cônjuge e $8 \%$ moram sozinhos. Os demais percentuais dividem-se entre outros familiares ou amigos. Cerca de 35\% dos discentes recebem alguma bolsa ou auxílio promovido pela Universidade, sendo $79 \%$ originada de auxílio acadêmico, $14 \%$ de auxílio moradia e $7 \%$ de bolsa trabalho.

Segundo uma das descrições, "ter que me sustentar, pagar aluguel e estudar é difícil. Estudar e saber que no fim do mês tem conta para pagar tira a concentração e o foco", afirma um dos discentes (31 anos).

Os resultados encontrados nessa pesquisa são condizentes com os descritos para as Universidades Federais do Rio de Janeiro, Minas Gerais e Brasília, em que a influência socioeconômica interfere diretamente na dedicação da disciplina fora da sala de aula, afetando o seu desenvolvimento acadêmico e comprometendo a aprendizagem significativa. ${ }^{4,18-20}$

Além disso, uma das interferências relacionadas às reprovações que incide diretamente na questão socioeconômica é relacionada ao coeficiente de rendimento acumulado. As reprovações diminuem a possibilidade do recebimento de "assistência estudantil", o que segundo algumas pesquisas relatam que influencia diretamente no processo de permanência prolongada do curso. ${ }^{21,22}$ Segundo Mazzetto et al. ${ }^{21} \mathrm{e}$ Cabrera et al. ${ }^{22} \mathrm{o}$ estudante que recebe apoio financeiro tem maiores condições de integração social e acadêmica.

\section{Detecção da dificuldade}

Química Geral é uma disciplina de importância fundamental e abrange um amplo conjunto de saberes, dando embasamento para explicação de como acontece os mecanismos e reações nas diversas áreas do conhecimento. Quando os alunos conseguem integrar os conceitos aprendidos com outras disciplinas como cálculo, física, biologia, genética, entre outras, há uma completa discussão dos conceitos, além da aplicação na vida contemporânea e nos setores em que é desenvolvida. No entanto, quando esse campo de visão não é vislumbrado, torna-se uma barreira para aprendizagem.

Para avaliar a perspectiva e o grau das dificuldades, os discentes pontuaram numa escala de 1 a 5 , em que 1 é nenhuma dificuldade e 5 é dificuldade alta, como os mesmos avaliavam a dificuldade na disciplina de Química Geral teórica, sendo: 1 - nenhuma; 2 - pouca; 3 - média; 4 - alta; 5 - altíssima (Figura 5).
$\mathrm{Na}$ análise dos estudantes, as maiores dificuldades estão relacionadas aos cálculos matemáticos e na base em química. Ao avaliarem os conteúdos que haviam maior dificuldade, verificou-se que a Estequiometria e o balanceamento, tópicos que envolvem cálculos matemáticos, apresentaram $69 \%$ da seleção dos discentes, seguidos de reações químicas (13\%), ligações químicas (8\%), estrutura atômica (2\%) e outros $(8 \%)$.

Avaliando-se de forma geral os motivos que contribuem para o alto índice de retenção, o grupo sustentou especificidades que apontam caraterísticas culturais referentes a educação básica. Na autoanálise, $84 \%$ consideram o Ensino Médio como fraco ou regular, 13\% bom, $3 \%$ muito bom e nenhum considerou ótimo. Complementando, na questão posterior, cerca de $32 \%$ dos indivíduos afirmaram que a maior dificuldade está relacionada a conteúdos importantes que não são vistos no Ensino Médio, seguidos de $24 \%$ que reconhecem a dificuldade pessoal nos conteúdos de química, $16 \%$ relacionam ao pouco tempo dedicados a estudar, $20 \%$ relacionam a falta de tempo devido ao trabalho e $8 \%$ atribuem a comunicação ou didática do docente.

No universo analisado, todos os estudantes cursaram o Ensino Médio em escolas públicas, sendo 3\% no Instituto Federal e 97\% em escolas estaduais. Além disso, esse curso abrange a inserção de estudantes do médio Solimões, com $89 \%$ sendo do próprio município, Coari, mas com representantes nas cidades vizinhas Manaus (3\%), Alvarães (5\%), Amaturá (3\%).

Na perspectiva de Gadotti ${ }^{23}$ o desempenho do sistema escolar não tem dado conta da universalização da educação básica de qualidade e essa falta é descrita em outros trabalhos científicos. . $^{40,24}$

Entre os fatores que podem explicar a grande dificuldade que os alunos encontram citam-se os três principais: a) heterogeneidade das turmas, ou seja, alunos com pouco entendimento dos conceitos que foram estudados no Ensino Médio, até alunos que possuem um bom e consistente domínio do assunto; b) quantidade de disciplinas de carga horária e c) dificuldade com o método de estudo continuado na universidade. ${ }^{3}$

As dificuldades detectadas podem ser correlacionadas com a falta de professores qualificados para dar aulas, comprometendo o desenvolvimento educacional dos estudantes e enfraquecendo a educação de base. ${ }^{24}$ Segundo o INEP, o desempenho insatisfatório de grande parte dos participantes, tanto provenientes de escolas públicas quanto de escolas privadas, remete a esse problema do déficit de qualidade do ensino no país. Verifica-se que, segundo os dados do MEC em $2010,{ }^{25}$ somente $13 \%$ dos professores de química em exercício

\section{Dificuldade}

Tempo para se dedicar a estudar

Metodologia de ensino

Linguagem acadêmica do livro

Base de Química

Cálculos matemáticos

Interpretação dos conteúdos

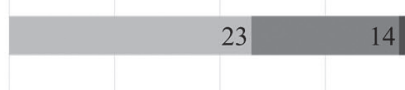

\section{6}

\begin{tabular}{llllll|}
12 & 14 & 46 & 14 & 14 \\
\hline
\end{tabular}

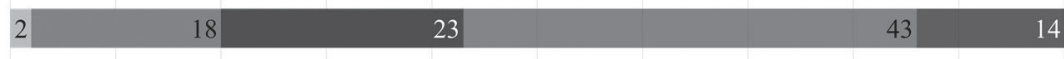

\begin{tabular}{lllll}
14 & 16 & 27 & 19 & 24 \\
\hline
\end{tabular}

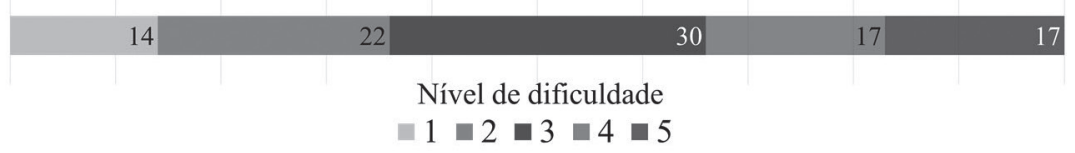

Figura 5. Tipos de dificuldades relatadas pelos discentes em Química Geral 
possuem formação na área. Esses dados formam problemas cíclicos pois os professores que ministram as aulas possuem dificuldade nas metodologias de ensino, repassando para os alunos, que acabam muitas vezes não gostando da disciplina e não apresentando base para a universidade. ${ }^{26,27}$

Dessa forma, o acúmulo de pequenas variáveis pode ocasionar graves problemas. Assim, os resultados desta pesquisa, como o pouco tempo para estudar, a quantidade de disciplinas e os fatores socioeconômicos, podem associar-se e comprometer a qualidade da aprendizagem, destacando os indícios da problemática envolvida.

\section{Intervenção}

As pesquisas são comumente voltadas para a evasão, no entanto, para que um estudante se desligue completamente de uma instituição de nível superior há um acúmulo de pequenos motivos que norteiam a decisão final. As reprovações recorrentes nas mesmas disciplinas são uma das principais causas da evasão nas licenciaturas, fazendo com que os discentes se desestimulem com o curso e não consigam atingir a meta de serem profissionais graduados na área.

Dessa forma, detectar ações que viabilizem uma erradicação ou minimização desse quadro torna-se uma contribuição imensurável para o setor educacional e de alto interesse para as comunidades científicas. Nessa perspectiva pôde-se avaliar a opinião discente sobre intervenções acerca dessa problemática, na qual os acadêmicos apontaram os pontos que poderiam ser avaliados para haver uma melhoria no aproveitamento da disciplina e, consequentemente, menor índice de reprovação relacionado tanto aos discentes quanto aos docentes.

Em relação ao discente, eles reconhecem que precisam dedicar-se mais à disciplina, disponibilizando mais tempo para estudar e uma busca maior de materiais didáticos complementares. E em relação aos docentes e à instituição, houve solicitações de aulas de nivelamento e maior comunicação entre os docentes e os discentes. Outro ponto relevante foi a aplicação de aulas contextualizadas e atividades lúdicas e experimentais a fim de aplicar os conteúdos teóricos.

A preocupação com a dificuldade dos discentes na disciplina de Química vêm fazendo com que pesquisas sejam desenvolvidas a fim de apresentar as causas e consequências desse déficit. Machado et al. ${ }^{19}$ e Campelo e Lins ${ }^{17}$ destacam que a retenção deve ser contabilizada como item de despesa para o estado no Ensino Superior, tanto no setor público quanto no privado, tendo em vista que são recursos investidos sem o devido retorno e que apresentam ociosidade de professores, funcionários, equipamentos e espaço físico.

Cabe destacar que os dados aprofundados como os encontrados nesse trabalho acerca da retenção na disciplina de Química geral no ensino superior brasileiro são pouco explorados, o que acarreta numa diminuta compreensão do problema. Os principais trabalhos evocam ações que podem auxiliar no processo de aprendizado, como o uso de artigos científicos nas aulas, tecnologia de informática e comunicação, uso de softwares, atividades lúdicas e experimentais, entre outras. ${ }^{3}$ Essas informações são de grande relevância para o aprimoramento das aulas, no entanto, esse assunto apresenta uma complexidade maior do que a abordada.

Os parâmetros metodológicos de Bean e Metzner ${ }^{10}$ também foram propostos por Pereira et al. ${ }^{2}$ ao avaliarem os fatores envolvidos no processo de permanência prolongada dos discentes na Universidade Federal do Espírito Santo, nos quais foram detectados 21 fatores intervenientes, destacando-se o desempenho acadêmico e o número de reprovações como as variáveis mais significativas. Outros fatores apontados na pesquisa desses autores foram o ambiente institucional, contexto familiar e condições financeiras dos acadêmicos.

A retenção em Química Geral é um problema notório e difícil de ser tratado, pois suas causas são de modo algum fáceis de detectar e isso é devido ao fato de que cada região, cada instituição de Ensino e cada estudante tem suas particularidades. ${ }^{28-30}$ No entanto, verificou-se por meio dessa pesquisa que há problemas fundamentais comuns nos cursos em que essa disciplina é ofertada e que dificultam a minimização destas taxas de retenção.

No trabalho de Francisco et al. ${ }^{29}$ os autores defendem a ampliação do tempo para discussões conceituais durante as aulas a fim de identificar as deficiências de conhecimento, organização e correlação de conceitos químicos. Para esses autores, é necessário que o docente tenha o controle do nível da turma para que as intervenções possam ocorrer de forma significativa.

Uma intervenção que vem sendo reportada com resultado satisfatório é o uso de curso de nivelamento, ou seja, curso de revisão ou preparatório para a disciplina de Química Geral antes do período letivo. Essa estratégia apresentou um declínio significativo das taxas de reprovação dos calouros na Universidade de Benedictine em Chicago, aumentando cerca de $50 \%$ as aprovações. ${ }^{6}$

Identificar as deficiências e dificuldades dos discentes é uma possibilidade de mudar o quadro atual de reprovações e, consequentemente, de evasão universitária. Em acréscimo, tem-se o aperfeiçoamento de processos de ensino e aprendizagem por meio de ferramentas que aproximem os discentes na aplicação e assimilação dos conteúdos. Dessa forma, a premissa da qualidade do ensino deve começar desde os primeiros períodos até o final da universidade, tendo os professores o papel de motivar os discentes a seguirem sua vocação em meio a todas as dificuldades que os acompanharão no caminho dessa longa jornada que é a formação no nível superior.

\section{CONCLUSÃO}

A retenção na disciplina de Química Geral é um problema comum nos cursos universitários e os resultados detectados neste artigo buscam contribuir para o alcance da erradicação ou minimização nas instituições de educação superior brasileiras, sejam elas públicas ou privadas.

Esta pesquisa apresenta, além dos fatores associados à retenção, as consequências institucionais e a influência da situação financeira dos discentes para o desempenho acadêmico. Com base nos resultados obtidos, sugere-se que a retenção resulta fundamentalmente nas seguintes variáveis: pouca afinidade com a disciplina, dificuldade socioeconômica, metodologia de estudo inadequada e deficiência no ensino de base, principalmente relacionada às disciplinas de ciências e matemática.

As soluções vislumbradas são cursos de nivelamento, estímulo dos acadêmicos e acompanhamento do desempenho parcial e contínuo, a fim de minimizar o efeito de retenção. Sugere-se a continuação das pesquisas nessa área envolvendo a perspectiva docente sobre esses índices, acompanhamento dos professores que ministram a disciplina e a correlação de dados entre os cursos que oferecem Química Geral.

Espera-se, com os resultados dessa pesquisa, contribuir com os estudos existentes sobre a evasão e retenção nos cursos de nível superior, criando subsídios que favoreçam estudos mais aprofundados sobre o tema e melhorando, assim, o nível de educação e desenvolvimento do país.

\section{REFERENCIAS}

1. http://portal.inep.gov.br/artigo/-/asset_publisher/B4AQV9zFY7Bv/ content/mec-e-inep-divulgam-dados-do-censo-da-educacaosuperior-2016/21206, acessada em janeiro de 2019.

2. Pereira, A. S; Carneiro, T. C. J; Brasil, G. H; Corassa, M. A. C.; Ensaio: aval. pol. públ. educ. 2015, 23, 1015. 
3. Pastoriza, B. S; Rosa, A. F. M; Araújo, M. B. C.; Amaral, S. T; Salgado, T. D. M.; Del Pino, J. C.; Renote 2007, 1.

4. Jesus, J. A; Silva, M. S; Santana, G. P.; Scientia Amazonia 2013, 2, 28.

5. Cracolice, M. S.; Busby, B. D.; J. Chem. Educ. 2015, 92, 179.

6. Stone, K. L.; Fendrick, S. E.; Educ. Sci. 2018, 8, 5.

7. Castro, K. S. S.; Teixeira, M. A. P.; Psicologia Argumento 2014, 32, 9.

8. Andrade, J. M.; Meira, G. R. J. M.; Vasconcelos, Z. B.; Psicol., Ciênc. Prof. 2002, 22, DOI: 10.1590/S1414-98932002000300008.

9. http://download.inep.gov.br/educacao_superior/censo_superior/ documentos/2016/notas_sobre_o_censo_da_educacao_superior_2016. pdf, acessada em janeiro de 2019.

10. Bean, J. P.; Metzner, B. S. A.; Review of Educational Research 1985, 55, 485 .

11. Sander, B.; Gestão da educação na América Latina: construção e reconstrução do conhecimento, $1^{\circ}$ ed., Autores Associados: Campinas, 1995.

12. Ciribelli, B. C. N.; Dissertação de mestrado, Universidade Federal de Juiz de Fora, Brasil, 2015.

13. Pimenta, S. G.; Saberes pedagógicos e atividade docente, Cortez: São Paulo, 1999

14. Guimarães, V. S.; Formação de professores: saberes, identidade e profissão, Papirus: Campinas, 2010.

15. Rêses, E. S. De vocação para profissão: Sindicalismo docente da educação básica no Brasil, $1^{\mathrm{a}}$ ed., Paralelo: Brasília, 2015

16. Yamaguchi, K. K. L; Furtado, M. A. S.; Rev. Educ. Online 2018, 28, 108.
17. Campello, A. V. C.; Lins, L. N.; Anais eletrônicos do Encontro Nacional de Engenharia de Producão, Rio de Janeiro, 2008. Disponível em http:// www.abepro.org.br/biblioteca/enegep2008_TN_STO_078_545_11614. pdf, acessado em janeiro de 2019.

18. Cunha, A. M; Tunes. E.; Silva, R. R.; Quim. Nova 2001, 24, 262.

19. Machado, S. P.; Melo Filho, J. M.; Pinto, A. C.; Quim. Nova 2005, 28, S41.

20. Braga, M. M.; Miranda-Pinto, C. O. B.; Cardeal, Z. L.; Quim. Nova 1997, 20, 438.

21. Mazzetto, S. E.; Bravo, C. C.; Carneiro, S.; Quim. Nova 2002, 25, 1204.

22. Cabrera, A.; Castañeda, M.; Nora, A.; Hengstler, D.; International Journal of Higher Education 1992, 63, 143.

23. Gadotti, M.; São Paulo em Perspectiva 2000, 14, 1.

24. Passoni, L. C.; Vega, M. R.; Giacomini, R.; Barreto, A. M. P.; Soares, J. dos S. C.; Crespo, L. C.; Quim. Nova Esc. 2012, 34, 201.

25. http://portal.mec.gov.br/component/tags/tag/32044-censo-da-educacaosuperior, acessada em janeiro de 2019.

26. Saviani, D.; Rev. Bras. Ed. 2009, 14, 40.

27. Francisco Jr., W. E. F. A.; Quim. Nova Esc. 2009, 31, 113.

28. Vanny, A. F. A.; Matos, W. H.; Almeida, M. D. B.; Montenegro, M. S. B.; Tecnia 2017, 2, 65.

29. Francisco, J. S.; Nicoll, G.; Trautmann, M.; J. Chem. Educ. 1998, 75, 210.

30. Santos Junior, J. S.; Real, G. C. M.; Avaliação 2017, 22, 385. 